\title{
Correction to: Brain PET amyloid and neurodegeneration biomarkers in the context of the 2018 NIA-AA research framework: an individual approach exploring clinical-biomarker mismatches and sociodemographic parameters
}

\author{
Artur Martins Coutinho ${ }^{1,2,3}$. Geraldo F. Busatto ${ }^{2,4}$. Fábio Henrique de Gobbi Porto ${ }^{2,4}$ - Daniele de Paula Faria ${ }^{1,2}$. \\ Carla Rachel Ono ${ }^{1,3}$. Alexandre Teles Garcez ${ }^{1,2}$ - Paula Squarzoni ${ }^{2,4}$ • Fábio Luiz de Souza Duran ${ }^{2,4}$. \\ Maira Okada de Oliveira ${ }^{5}$ • Eduardo Sturzeneker Tres $^{5} \cdot$ Sonia Maria Dozzi Brucki ${ }^{5} \cdot$ Orestes Vicente Forlenza $^{6}$. \\ Ricardo Nitrini ${ }^{5}$ - Carlos Alberto Buchpiguel ${ }^{1,2,3}$
}

Published online: 26 June 2020

C Springer-Verlag GmbH Germany, part of Springer Nature 2020

\section{Correction to: Eur J Nucl Med Mol Imaging. https://doi.org/10.1007/s00259-020-04714-0}

In the last paragraph of the subsession "Recruitment of the study population and clinical Evaluation" (Material and methods session) where it is read:

Finally, all participants were classified concerning their socioeconomic status (SES) using a five-category scale (from Athe highest, to D - the lowest) validated for use in our country, namely the ABA scale. The ABA scale is based on monthly financial incomes from each family. " $A$ " represents the upper income socioeconomic class, "B" the upper middle class, "C" lower middle class, and " $\mathrm{D}$ " the lowest-income class [29] (http://www.aba.com.br/wp-content/uploads/content/ 7727632a373615b34f2a5726fcc5c9e2.pdf - content in portuguese).

This article is part of the Topical Collection on Erratum.

The online version of the original article can be found at https://doi.org/ $10.1007 / \mathrm{s} 00259-020-04714-0$

Artur Martins Coutinho

arturcoutinho@gmail.com

1 Laboratory of NuclearMedicine (LIM43), Department of Radiology and Oncology, Faculdade deMedicina FMUSP, Universidade de Sao Paulo, Sao Paulo, SP, Brazil

2 Nucleo de Apoio a Pesquisa em Neurociência Aplicada (NAPNA), Universidade de Sao Paulo, Sao Paulo, SP, Brazil

3 Centro deMedicina Nuclear do Instituto de Radiologia, Hospital das Clínicas da Faculdade deMedicina da Universidade de São Paulo, $2^{\circ}$ andar, Rua Doutor Ovídio Pires de Campos, 872, Cerqueira Cesar, São Paulo, SP, Brazil
It should be stated:

Finally, all participants were classified concerning their socioeconomic status (SES) using a five-category scale (from Athe highest, to E- the lowest) validated for use in our country, namely the ABA scale. The ABA scale is based on monthly financial incomes from each family. "A" represents the upper income socioeconomic class, "B" the upper middle class, "C" lower middle class, and "D" and "E" the lowest-income classes [29] (http://www.aba.com.br/wp-content/uploads/content/ 7727632a373615b34f2a5726fcc5c9e2.pdf - content in portuguese).

In the Results session, in the end of the "Clinical and demographic data" subsession, the following statement is missing: No individuals were classified according to their SES under the "E" class.

4 Laboratory of Psychiatric Neuroimaging (LIM 21), Department of Psychiatry, Faculdade de Medicina FMUSP, Universidade de Sao Paulo, Sao Paulo, SP, Brazil

5 Department of Neurology, Faculdade de Medicina FMUSP, Universidade de Sao Paulo, Sao Paulo, SP, Brazil

6 Laboratory of Neuroscience (LIM 27), Department of Psychiatry, Faculdade de Medicina FMUSP, Universidade de Sao Paulo, Sao Paulo, SP, Brazil 
In addition to Reference 29 [ABA. Critério de classificação sócio-econômica. 2007. http://www.aba.com.br/wp-content/ uploads/content/7727632a373615b34f2a5726fcc5c9e2.pdf content in portuguese). Assessed 7 Mar 2018.]:
- MATTAR, Fauze Najib. Análise crítica dos estudos de estratificação socioeconômicos da ABAABIPEME. Revista de Administração, v. 30, n.1, p. 57-74, jan/mar 1995.

Publisher's note Springer Nature remains neutral with regard to jurisdictional claims in published maps and institutional affiliations. 